\title{
Dietary Diversity and Associated Factors Among Adult HIV Positive Patients on Anti-Retroviral Therapy in Public Hospitals of Kembata Tembaro Zone, Southern Ethiopia
}

This article was published in the following Dove Press journal:

HIVIAIDS - Research and Palliative Care

\author{
Melese Markos' \\ Tsegaye Lolaso $\mathbb{D}^{2}$ \\ Abrham Mengistu ${ }^{3}$ \\ Zerihun Tariku $\mathbb{D}^{\prime}$ \\ 'Department of Public Health, College of \\ Medicine and Health Science, Dire Dawa \\ University, Dire Dawa, Ethiopia; ${ }^{2}$ School \\ of Public Health, College of Health and \\ Medicine Science, Wolaita Sodo \\ University, Wolaita Sodo, Ethiopia; \\ ${ }^{3}$ Department of Public Health, College of \\ Health and Medicine Science, Wachamo \\ University, Hossaina, Ethiopia
}

Correspondence: Melese Markos Tel +25I-916-138-37|

Email melesemarkos@gmail.com
Background: Nutrition is a significant factor in all stages of HIV. Dietary management of HIV-positive patients is key to supporting their capacity to continue participating in the workforce and contributing to socio-economic growth. Few studies have been conducted regarding this important public health problem of dietary diversity throughout the developing countries including Ethiopia. Therefore, this study assesses the magnitude and factors associated with dietary diversity among HIV-positive patients attending antiretroviral therapy (ART) clinics at Public Hospitals in Kembata Tembaro Zoni, Southern Ethiopia.

Methods and Materials: An institutional-based cross-sectional study was conducted from January 01/2019 to 30/2019 on 341 adult HIV-positive patients on ART at two randomly selected public hospitals in the study area. A systematic random sampling technique was applied to select study subjects from each facility proportionally. Bivariable and multivariable logistic regression analyses were done to identify factors associated with individual dietary diversity. Logistic regression analysis with $95 \%$ confidence interval (CI) was estimated to measure the strength of association. Level of significance for statistical tests was set at $\mathrm{p}<0.05$.

Results: This study shows $60.1 \%$ (95\% CI: 55-65) of patients had inadequate dietary diversity. Average monthly income of less than 1000 Ethiopian Birr (AOR: 1.82, 95\% CI: 1.04-3.17), being female $(\mathrm{AOR}=2.99,95 \% \mathrm{CI}: 1.67-5.37)$, duration of ART less than 1 year $(\mathrm{AOR}=3.77$, 95\% CI: $1.42-10.02$ ) and lack of dietary counseling (AOR $=0.54,95 \% \mathrm{CI}: 0.30-0.97$ ) were factors associated with low dietary diversity.

Conclusion: Low dietary diversity was a major nutritional problem in HIV-positive patients. Low average monthly income, being female, duration of participants on ART, and lack of dietary counseling were the factors associated with low dietary diversity. To alleviate these problems, exceptional attention in nutritional care should be given to HIV-positive patients and they require appropriate counseling and support during early initiation of ART. Keywords: dietary diversity, HIV positives, patients, southern, Ethiopia

\section{Introduction}

Dietary diversity is a qualitative measure of food consumption that reveals household access to a variety of foods; at a different level, it reflects the nutrient adequacy of the diet. ${ }^{1}$ Ensuring adequate food and nourishment to meet people's basic needs for wellbeing, growth and development have been a long-lasting challenge for developing countries, especially in Africa. This was further impaired by the arrival of HIV/AIDS. ${ }^{2,3}$ 
The Global AIDS Update 2016 report shows that approximately 36.7 million people are currently living with HIV and tens of millions of people have died of AIDS-related causes since the beginning of the epidemic. ${ }^{4}$ HIV not only affects the health of individuals, but also households, communities, development, and economic growth of nations. ${ }^{4,5}$

Nutrition is a significant factor at all stages of HIV. Clinical studies show that People Living With HIV (PLHIV) have reduced appetite and ability to consume food, as well as a higher incidence of diarrhea resulting in malabsorption and nutrient losses. ${ }^{6}$ Studies have also found that PLHIV are more likely to be deficient in vitamin $A$, vitamin $B 12$, vitamin $C$, vitamin $D$, selenium, zinc, and iron. These micronutrient deficiencies, particularly vitamin B12, zinc, and selenium, have been associated with decreased immune function and a higher risk of disease progression in PLHIV. ${ }^{6}$

Nutritional complications are amongst the first harmful effects of HIV infection. These problems are due to insufficient food consumption and altered metabolic situations, aggravating the reduced balance of energy and nutrients in patients even when they are treated with antiretroviral therapy (ART). ${ }^{7,8}$ Nutrition is a significant component of inclusive care for HIV-positive patients and is particularly so in resource-limited settings where malnutrition and food insecurity are endemic. ${ }^{9}$

Dietary management of HIV-positive patients is key to supporting their capacity to continue participating in the workforce and contributing to socio-economic growth. Inadequate dietary intake contributes to micronutrient insufficiencies that lead to further HIV/AIDS disease advancement and to the reduction of CD4 count which increases risk of opportunistic infections in addition to oxidative stress. ${ }^{1,10}$

HIV has been found to affect nutritional status by increasing energy requirements, decreasing food intake, and badly disturbing nutrient absorption and metabolism. Inability to meet nutritional needs may lead to reduced immunity and increased vulnerability to opportunistic infections (OIs), which can lead to further malnutrition. ${ }^{11,12}$

The association between HIV infection and nutrition and the influence of HIV on nutrition is difficult to determine. ${ }^{13}$ Micronutrients are important for sustaining suitable immunological responses so preserving proper nutrition, weight, and immune systems should delay disease advancement, delay the asymptomatic phase and increase lifespan.
However, large numbers of HIV patients have less than ideal eating circumstances and low energy consumption. ${ }^{14-16}$

Dietary diversity, the consumption of a sufficient variety of food types, is a characteristic of dietary quality and can be considered as an indicator of overall nutritional adequacy. ${ }^{14,17}$ Utilizing a diversified diet among PLHIV is still poor among resource-limited nations in Africa. For instance, studies done in Kenya, Rwanda, Nigeria, and Uganda show that $43 \%$ to $62.3 \%$ of PLHIV had low dietary diversity. ${ }^{9,18-20}$ According to studies done in Rwanda, Uganda, Nigeria, and Kenya, factors including low educational and economic status; mental health status, physical health status; purchase of food and absence of nutritional counseling were identified as being associated with dietary diversity among HIV patients on ART. ${ }^{9,20,21}$

Studies done in Ethiopia show that low dietary diversity among HIV-positive patients were at levels of $28.7 \%$ to $71 \%$ and that lower income or wealth status, occupational status, educational status, separated from husband/ wife, media exposure in household, nutritional counseling, shorter duration of ART, taking cotrimoxazole prophylaxis are among the most common factors which affect dietary diversity status of HIV patients on ART. , $11,14,19,22^{2}$

Ethiopia had made a notable effort to address the influence of HIV/AIDS on nutrition by establishing national guidelines for taking action to deliver quality care and support to HIV-positive patients. ${ }^{23}$ Also, it provided livelihood support and food support and strengthened communitybased nutrition care and support activities for PLHIV through health extension workers and agriculture extension workers in addition to ART, care, and support. ${ }^{24,25}$

There is an interaction between diversified diet consumption, functional status and HIV/AIDS and nutritional status. Few studies have been conducted regarding this important public health problem in developing countries including Ethiopia and there is a scarcity of research done on dietary diversity among PLHIV in our study area. Hence, the purpose of this study was to assess the magnitude and factors of dietary diversity among HIV patients attending ART clinics at Public Hospitals in Kembata Tembaro Zone, Southern Ethiopia.

\section{Methods and Materials Study Design and Setting}

An institution-based cross-sectional study design was used. The study was done in Kembata Tembaro Zone, Southern Ethiopia. Kembata Tembaro Zone is one of the 
central ones in South Nation Nationality People Region (SNNPR) and Durame is its capital town. The town is $119 \mathrm{~km}$ away from Hawassa, the capital of SNNPR and $306 \mathrm{~km}$ away from Addis Ababa, the capital of Ethiopia. There are 31 health centers, three primary hospitals and one general hospital in the zone. Six public health centers and four public hospitals provide ART services in the zone. The study was conducted from January 01-30/ 2019. There were 971 HIV-positive patients who were receiving ART from different health facilities, among those 405 were in Durame General hospital and 226 were in Shinshicho Primary Hospital according to a zonal report. ${ }^{26}$

All HIV-positive adults on ART in the public hospitals in the zone were the source population. All HIV-positive adults who were attending ART services at selected public hospitals in the zone were the study population. All those on ART and aged 18 years and above were included in this study; those who were seriously ill, or who had taken part in unusual special feasts or occasions away from home within the last 24 hour preceding data collection were excluded from the study.

\section{Sample Size Determination and Sampling Procedure}

The sample size for the magnitude of dietary diversity was estimated using the formula $\mathrm{n}=\frac{(\mathrm{z} \alpha / 2)^{2} \times \mathrm{P}(1-\mathrm{P})}{(d)^{2}}$. For a proportional single population the prevalence of dietary diversity among HIV patients was $28.7 \%{ }^{7}$, confidence level at $95 \%$ (1.96), precision (d) 0.05 , and $10 \%$ nonresponse. Hence, yielding the final sample size of 347 . Of four public hospitals in the zone, which are currently offering ART service, two were included in the study by using a simple random sampling technique (lottery method), one general and one district hospital, namely, Durame General Hospital and Shinshicho Primary Hospital were selected. The sample size was proportionally allocated to the selected hospitals and the study participants were selected using a systematic random sampling technique based on patient ART unique identification number (MRN).

\section{Data Collection Methods Interview-Administered Questionnaire}

Data were collected by interview administered methods using structured and pre-tested questionnaire and record review. Socio-demographic and behavioral data were collected from all eligible participants using the pretested structured questionnaire. Household food security scale was assessed by a standard questionnaire developed to administer the Household Food Insecurity Access Scale

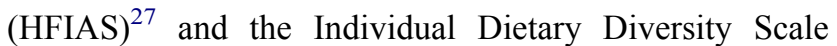
(IDDS) was administered using a standard questionnaire developed by Food and Nutrition Technical Assistant (FANTA). ${ }^{1}$ Record review: data were collected by reviewing each patient's medical record using structured checklists. Anthropometric data were collected using a calibrated weight scale used in medical set-up and height was measured using a portable height measuring board. Data were collected by four diploma nurses working in the ART clinic of the hospitals selected. One health officer was recruited as a supervisor during data collection.

\section{Measurements and Variables}

Dietary diversity score of the study participants was completed primarily by listing all food items consumed by participants (both in and out of home). Listing of food was from breakfast then lunch and dinner while snacks were considered to be eaten before or after the main meal. Then based on the Food and Agriculture Organization $^{1}$ recommendation, foods eaten by the respondents were classified into 9 food groups: starchy staples, dark leafy green vegetables, other vitamin A rich fruits and vegetables, other fruits and vegetables, organ meat, meat and fish, eggs, legumes, nuts and seeds, milk and dairy products. Respondents scored 1 point if they consumed at least once during the last 24 hours any of the foods within each subgroup, and 0 points if they never consumed the food. The Individual Dietary Diversity Score was calculated by computing of food groups consumed over 24 hours. The total individual food scores were first categorized into two categories; scores below the mean value of 4.3 were considered low dietary diversity scores and scores above the mean value of 4.3 were considered high dietary diversity scores.

Household food insecurity/security status was calculated based on nine questions of food access and was categorized into $1=$ Food Secure, $2=$ Food Insecure. When a participants scored $\leq 2$ affirmative answers they were considered as food secure; while participants who scored more than 2 affirmative answers were considered as food insecure.

\section{Anthropometric Measurement}

The study subjects' weight was measured using a standard digital weight scale that is used in the medical set-up and 
recorded to the nearest $0.1 \mathrm{~kg}$. It was calibrated against known weight. During the measurement, the study participants had on light clothes, and shoes were taken off. Similarly, height measurements were carried out while the participant removed his/her shoes, stood erect, looking straight in a horizontal plane with feet together and knees straight and the measurements were recorded to the nearest $0.1 \mathrm{~cm}$.

Dietary diversity is the number of reported different foods and food groups consumed in a household over 24 hours. This includes food groups consumed inside or outside the home. It is classified as high or low based on mean value. Which score below the mean value was low and which score above the mean value was high dietary diversity was based on FANTA/FAO recommendations. ${ }^{1}$

\section{Data Quality Control}

Data were collected by the adapted standard questionnaire of Food and Nutrition Technical Assistant (FANTA) which is validated according to developing country. The questionnaires at first are prepared in English and translated into Amharic language, and then back to English by language experts and researchers to keep the consistency of the questionnaires. Before the data collection, the questionnaire was pre-tested on $5 \%$ of the sample size at Mudula Primary Hospital; furthermore, a two-day intensive training was given to the data collectors and supervisors by the principal investigators. Calibration of anthropometric measuring weight scale was done using objects with known weight.

\section{Data Processing and Analysis}

All filled questionnaires were checked for completeness and consistency and entered into Epidata 3.1 software. Then the data were transferred to SPSS Version 22 for additional analysis. Descriptive statistics: frequency, proportion, mean and standard deviation were used to summarize the variable. Variables with a p-value of less than 0.25 in the bivariable analysis were entered into final model. A multivariable logistic regression model was done to control for all possible confounders. Most of assumption of logistic regression were checked using suitable methods. Model adequacy was checked by using Hosmer-Lemeshow goodness of fit test. Finally, variables with p-value less than 0.05 in multivariable logistic regression analysis were considered as significant association with dietary diversity.

\section{Ethical Considerations}

The study ethical procedure was cleared by the Dire Dawa University, Research Ethics Review Committee (RERC). The permission and agreement consent was obtained from Southern Nations Nationalities and Peoples Regional Health office, Kembata Tembaro Zone Health Department and selected hospitals prior to the study. Voluntary written and signed consent was obtained from each study participant after informing the objective, confidentiality, right to withdrawal, benefit, and risks of the study and that this study was conducted in accordance with the Declaration of Helsinki.

\section{Result}

\section{Socio-Demographic and Economic Characteristics}

In this study, out of the 347 study participants initially sampled in the study, 341 participated, making a response rate of $98.2 \%$. Of these $195(57.2 \%)$ were females and more than threequarters (79.5\%) were Kambata ethnic group. Near to half of participants (46.3\%) were in the age group of 26-35 years with a mean $( \pm \mathrm{SD})$ age of $36.1( \pm 8.1)$ years. Two-thirds $(66.6 \%)$ of the study participants were married. Two hundred and four (59.8\%) were urban residents, about half of the study participants $(51.3 \%)$ had elementary education and $68.6 \%$ had a male-headed household. One hundred and ninety-six (57.5\%) earned less than 1000 ETB average monthly income. Above two-thirds of study participants (70.4\%) were living in a household size of five and below (Table 1).

\section{Health-Related Characteristic}

The majority of the study subjects $(273 ; 80.1 \%)$ were in WHO clinical stages I \& II, and 310 (90.9\%) had good treatment adherence. Regarding functional status, 317 (93\%) of respondents could work their daily activities. The majority of respondents $(291 ; 85.3 \%)$ were taking cotrimoxazole prophylaxis. The mean of their duration on ART was 66 months (SD \pm 35.07$)$. Fifty-nine (17.3\%) were identified to have other illnesses (OIs) of any type. The greatest reported OI was pneumonia $(27 ; 45.8 \%$ ) (Table 2).

\section{Nutritional and Behavioral Characteristics}

The mean BMI value of the study participants was $20.6 \mathrm{~kg} / \mathrm{m}^{2}$ with a minimum of $12.7 \mathrm{~kg} / \mathrm{m}^{2}$ and maximum of $35.86 \mathrm{~kg} / \mathrm{m}^{2}$. Among the total respondents, 85 (24.9\%) were underweight and $66.6 \%$ said that their primary source of food was purchased. More than half of the respondents $(201 ; 58.9 \%)$ reported their actual daily meal pattern to be less than 3 times per day. Concerning behavioral factors, the majority i.e. $296(86.8 \%), 280(82.1 \%)$ and $266(78 \%)$ of study subjects 
Table I Socio-Demographic and Economic Characteristics of Adult HIV-Positive Patients on Antiretroviral Therapy in Public Hospitals of Kembata Tembaro Zone, Southern Ethiopia 2019 $(n=34 I)$

\begin{tabular}{|c|c|c|c|}
\hline Variables & Category & Frequency & Percent \\
\hline \multirow[t]{2}{*}{ Sex } & Male & 146 & 42.8 \\
\hline & Female & 195 & 57.2 \\
\hline \multirow[t]{4}{*}{ Age in years } & $18-25$ & 23 & 6.8 \\
\hline & $26-35$ & 158 & 46.3 \\
\hline & $36-44$ & 98 & 28.7 \\
\hline & $\geq 45$ & 62 & 18.2 \\
\hline \multirow[t]{2}{*}{ Residence } & Urban & 204 & 59.8 \\
\hline & Rural & 137 & 40.2 \\
\hline \multirow[t]{4}{*}{ Marital status } & Single & 37 & 10.8 \\
\hline & Married & 227 & 66.6 \\
\hline & Divorced & 15 & 4.4 \\
\hline & Widowed & 62 & 18.2 \\
\hline \multirow[t]{2}{*}{ Family size } & $\leq 5$ & 240 & 70.4 \\
\hline & $>5$ & 101 & 29.6 \\
\hline \multirow[t]{4}{*}{ Educational status } & $\begin{array}{l}\text { No formal } \\
\text { education }\end{array}$ & & 15.5 \\
\hline & Read and write & 20 & 5.9 \\
\hline & Elementary & 175 & 51.3 \\
\hline & $\begin{array}{l}\text { Secondary and } \\
\text { above }\end{array}$ & 93 & 27.3 \\
\hline \multirow[t]{5}{*}{ Ethnicity } & Kambata & 271 & 79.5 \\
\hline & Hadiya & 31 & 9.1 \\
\hline & Wolaita & 20 & 5.9 \\
\hline & Gurage & II & 3.2 \\
\hline & Others* & 8 & 2.3 \\
\hline \multirow[t]{4}{*}{ Religion } & Protestant & 272 & 79.8 \\
\hline & Orthodox & 45 & 13.2 \\
\hline & Catholic & 17 & 5 \\
\hline & Muslim & 7 & 2 \\
\hline \multirow[t]{8}{*}{ Occupational status } & Farmer & 89 & 26.2 \\
\hline & Merchant & 82 & 24 \\
\hline & Government & 44 & 12.9 \\
\hline & employer & & \\
\hline & House wife & 69 & 20.2 \\
\hline & Daily labor & 31 & 9.1 \\
\hline & Student & 8 & 2.3 \\
\hline & Self-employer & 18 & 5.3 \\
\hline \multirow{2}{*}{$\begin{array}{l}\text { Sex of head of } \\
\text { household }\end{array}$} & Male & 234 & 68.6 \\
\hline & Female & 107 & 31.4 \\
\hline \multirow{2}{*}{$\begin{array}{l}\text { Average monthly } \\
\text { income }\end{array}$} & $\leq 1000$ & 196 & 57.5 \\
\hline & $>1000$ & 145 & 42.5 \\
\hline \multirow[t]{2}{*}{ Living condition } & Alone & 24 & 7 \\
\hline & With others & 317 & 93 \\
\hline
\end{tabular}

Note: *Tigre, Amhara, Oromo, Gurage.
Table 2 Health-Related Characteristics of Adult HIV-Positive Patients on Antiretroviral Therapy in Public Hospitals of Kembata Tembaro Zone, Southern Ethiopia $2019(n=341)$

\begin{tabular}{|c|c|c|c|c|}
\hline Variables & \multicolumn{2}{|c|}{ Category } & Frequency & Percentage \\
\hline $\begin{array}{l}\text { CD4+ T cell } \\
\text { count (cell/mm³) }\end{array}$ & \multicolumn{2}{|l|}{$\begin{array}{l}<200 \\
200-350 \\
351-500 \\
\geq 500\end{array}$} & $\begin{array}{l}40 \\
61 \\
67 \\
173\end{array}$ & $\begin{array}{l}11.7 \\
17.9 \\
19.7 \\
50.7\end{array}$ \\
\hline $\begin{array}{l}\text { WHO clinical } \\
\text { stage }\end{array}$ & \multicolumn{2}{|c|}{$\begin{array}{l}\text { Stage I \& II } \\
\text { Stage III \& IV }\end{array}$} & $\begin{array}{l}273 \\
68\end{array}$ & $\begin{array}{l}80.1 \\
19.9\end{array}$ \\
\hline ART regimens & \multicolumn{2}{|l|}{$\begin{array}{l}\text { Ist line } \\
\text { 2nd line }\end{array}$} & $\begin{array}{l}310 \\
31\end{array}$ & $\begin{array}{l}90.9 \\
9.1\end{array}$ \\
\hline Duration on ART & \multicolumn{2}{|c|}{$\begin{array}{l}\leq 12 \text { months } \\
>12 \text { months }\end{array}$} & $\begin{array}{l}28 \\
313\end{array}$ & $\begin{array}{l}8.2 \\
91.8\end{array}$ \\
\hline CPT prophylaxis & \multicolumn{2}{|l|}{$\begin{array}{l}\text { Yes } \\
\text { No }\end{array}$} & $\begin{array}{l}291 \\
50\end{array}$ & $\begin{array}{l}85.3 \\
14.7\end{array}$ \\
\hline $\begin{array}{l}\text { Any support } \\
\text { other than } \\
\text { medication }\end{array}$ & \multicolumn{2}{|l|}{$\begin{array}{l}\text { No } \\
\text { Yes }\end{array}$} & $\begin{array}{l}258 \\
83\end{array}$ & $\begin{array}{l}82.7 \\
17.3\end{array}$ \\
\hline $\begin{array}{l}\text { Adherence to } \\
\text { ART }\end{array}$ & \multicolumn{2}{|l|}{$\begin{array}{l}\text { Good } \\
\text { Poor }\end{array}$} & $\begin{array}{l}310 \\
31\end{array}$ & $\begin{array}{l}90.9 \\
9.1\end{array}$ \\
\hline Functional status & \multicolumn{2}{|c|}{$\begin{array}{l}\text { Working } \\
\text { Ambulatory }\end{array}$} & $\begin{array}{l}317 \\
24\end{array}$ & $\begin{array}{l}93 \\
7\end{array}$ \\
\hline $\begin{array}{l}\text { Other person } \\
\text { living with HIV on } \\
\text { ART in the family }\end{array}$ & \multicolumn{2}{|l|}{$\begin{array}{l}\text { No } \\
\text { Yes }\end{array}$} & $\begin{array}{l}186 \\
154\end{array}$ & $\begin{array}{l}54.8 \\
45.2\end{array}$ \\
\hline \multirow{2}{*}{$\begin{array}{l}\text { Developing } \\
\text { current or past } \\
\text { six months Ols }\end{array}$} & \multicolumn{2}{|l|}{$\begin{array}{l}\text { No } \\
\text { Yes }\end{array}$} & $\begin{array}{l}282 \\
59\end{array}$ & $\begin{array}{l}82.7 \\
17.3\end{array}$ \\
\hline & Disease & $\begin{array}{l}\text { TB } \\
\text { Pneumonia } \\
\text { Oral rush } \\
\text { Diarrhea }\end{array}$ & $\begin{array}{l}8 \\
27 \\
18 \\
10\end{array}$ & $\begin{array}{l}13.6 \\
45.8 \\
30.5 \\
16.9\end{array}$ \\
\hline
\end{tabular}

stated that they do not smoke cigarette, do not drink alcohol and do not use khat respectively. Eighty-three (24.3\%) study subjects stated that they got support from organizations that provide ART services and among those the greatest reported support was money $(47 ; 56.6 \%)$ (Table 3$)$.

\section{Measurements of Dietary Diversity of the Study Participants}

This study revealed that low dietary diversity among HIV patients on ART was at a level of $60.1 \%$ (95\%, CI: 55.0, 65.0). Concerning dietary pattern, starchy staples $(89.4 \%)$, 
Table 3 Nutritional and Behavioral Characteristics of ART Patients in Public Hospitals at Kembata Tembaro Zone, Southern Ethiopia, $2019(n=341)$

\begin{tabular}{|c|c|c|c|}
\hline Variable & Category & Frequency & Percent \\
\hline $\begin{array}{l}\text { Household food security } \\
\text { status }\end{array}$ & $\begin{array}{l}\text { Secure } \\
\text { Insecure }\end{array}$ & $\begin{array}{l}138 \\
203\end{array}$ & $\begin{array}{l}40.5 \\
59.5\end{array}$ \\
\hline Meal frequency & $\begin{array}{l}\leq 3 \text { times } \\
>3 \text { times }\end{array}$ & $\begin{array}{l}207 \\
134\end{array}$ & $\begin{array}{l}60.5 \\
39.5\end{array}$ \\
\hline BMI & $\begin{array}{l}<18.5 \\
\geq 18.5\end{array}$ & $\begin{array}{l}85 \\
256\end{array}$ & $\begin{array}{l}24.9 \\
75.1\end{array}$ \\
\hline Dietary counseling & $\begin{array}{l}\text { Yes } \\
\text { No }\end{array}$ & $\begin{array}{l}247 \\
94\end{array}$ & $\begin{array}{l}72.4 \\
27.6\end{array}$ \\
\hline Cigarette smoker & $\begin{array}{l}\text { Yes } \\
\text { No }\end{array}$ & $\begin{array}{l}45 \\
296\end{array}$ & $\begin{array}{l}13.2 \\
86.8\end{array}$ \\
\hline Alcohol intake & $\begin{array}{l}\text { Yes } \\
\text { No }\end{array}$ & $\begin{array}{l}61 \\
280\end{array}$ & $\begin{array}{l}17.9 \\
82.1\end{array}$ \\
\hline Khat chewing & $\begin{array}{l}\text { Yes } \\
\text { No }\end{array}$ & $\begin{array}{l}75 \\
266\end{array}$ & $\begin{array}{l}22 \\
78\end{array}$ \\
\hline $\begin{array}{l}\text { Any support other than } \\
\text { medication }\end{array}$ & $\begin{array}{l}\text { No } \\
\text { Yes } \\
\text { Support } \\
\text { Money } \\
\text { Food } \\
\text { Loan } \\
\text { Equipment }\end{array}$ & $\begin{array}{l}258 \\
83 \\
47 \\
46 \\
11 \\
1\end{array}$ & $\begin{array}{l}75.7 \\
24.3 \\
56.6 \\
51.8 \\
13.3 \\
1.2\end{array}$ \\
\hline $\begin{array}{l}\text { Primary household source } \\
\text { of food }\end{array}$ & $\begin{array}{l}\text { Own } \\
\text { production } \\
\text { Purchased } \\
\text { Borrowed, } \\
\text { gift } \\
\text { Food aid }\end{array}$ & $\begin{array}{l}100 \\
227 \\
13 \\
1\end{array}$ & $\begin{array}{l}29.3 \\
66.6 \\
3.8 \\
0.3\end{array}$ \\
\hline
\end{tabular}

other fruits and vegetables (65.7\%) and legumes, nuts, and seeds $(63.0 \%)$ were the three food groups predominantly consumed by respondents who had high dietary diversity. Eggs $(27.9 \%)$, meat and fish (16.1\%) and organ meat (5.3\%) were food groups consumed by respondents who had low dietary diversity (Figure 1).

\section{Factors Associated with Level of Dietary Diversity}

In bivariate logistic regression indicators, sex of the respondents, occupational status, current residence, average monthly income, advanced AIDS stage III and IV, duration of ART, dietary counseling, meal frequency, absence of any support and food security status was associated with dietary diversity (Table 4).
In multivariable logistic regression analyses, females were three times more likely to report inadequate dietary diversity than males (AOR $=2.99,95 \%$ CI: 1.67-5.37). Participants with less than 12 month duration of ART were four times more likely to report inadequate dietary diversity than those with more than 12 months on ART (AOR $=3.77,95 \%$ CI: $1.42-$ 10.02). Patients with average monthly household income less than 1000 ETB were 1.82 times more likely to report inadequate dietary diversity than those with an income greater than 1000 ETB (AOR: 1.82, 95\% CI: 1.04-3.17). It was noticed that patients who received dietary counselling were $46 \%$ less likely to have inadequate dietary diversity than those who did not have dietary counselling (AOR $=0.54,95 \%$ CI: $0.30-$ 0.97) (Table 4).

\section{Discussion}

This study assessed the magnitude and factors of dietary diversity among adult patients on ART. Monthly income, sex, duration of participants on ART and dietary counselling were the factors associated with dietary diversity among adults on ART.

The overall magnitude of low dietary diversity in the current study was $60.1 \%$. The result was consistent with studies done in Mettema (58.8\%), ${ }^{14}$ Nigeria $(62.3 \%),{ }^{18}$ and Jimma (55.8\%); ${ }^{28}$ whereas, it was higher than those of studies done in Hiwot Fana and Dilchora Hospitals ART clinics in eastern Ethiopia (28.7\%), ${ }^{7}$ Butajira $(38.8 \%),{ }^{29}$ Kenya $(37.3 \%),{ }^{9}$ and Rwanda $(43 \%),{ }^{20}$ and it was lower than instudies conducted in Ambo (71\%), ${ }^{11}$ Dabra Tebor (67.6\%), ${ }^{19}$ Hossana $(69.4 \%),{ }^{30}$ and east Gojjam $(70.5 \%){ }^{22}$ This difference might be due to differences in study locations, seasonal variability, socioeconomic status of participants and cut-off points used to determine the outcome variable.

This study revealed a strong association between sex (gender) and low dietary diversity score. Females were three times more likely to have low dietary diversity than males. This result is in line with a study finding of Ambo town, West Shoa Zone Ethiopia that males were less likely to have low dietary diversity than females. ${ }^{11}$ The possible reason was that females have more difficulty than men in accessing resources including land, credit, and agricultural commodities and also females were less likely to be employed and unable be decision-makers in households and therefore could not get access to foods that meet their needs.

In this study monthly income was another predictor of dietary diversity among the study participants. Those who 


\section{Food Consumption}

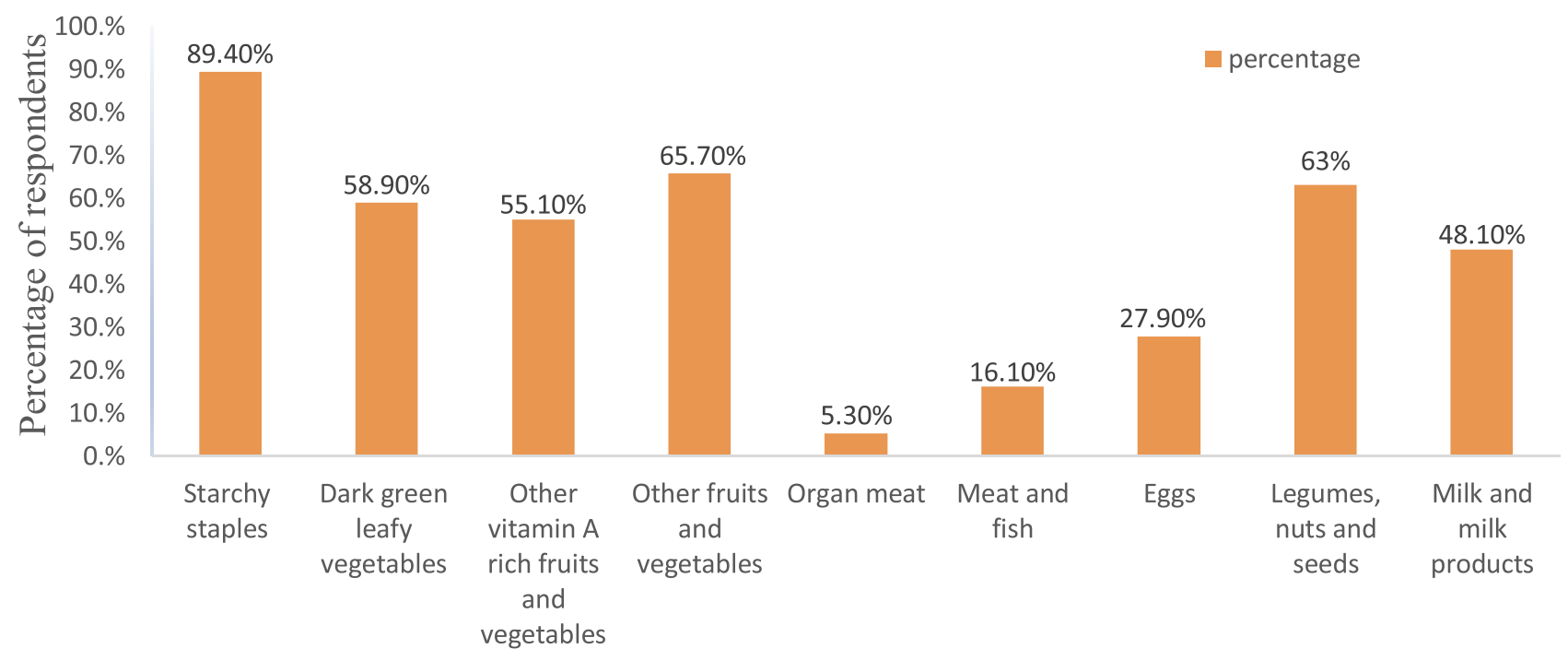

\section{Food group}

Figure I Twenty-four-hour food group consumption of adult HIV-Positive Patients on Antiretroviral Therapy in public hospitals of Kembata Tembaro Zone, Southern Ethiopia $2019(n=341)$.

earn a monthly income of $\leq 1000$ ETB were two times more likely to have low dietary diversity than those who earn $>1000$ Ethiopian birrs. This result is similar to studies conducted at Ambo town, West Shoa Zone, Ethiopia, ${ }^{11}$ Mettema, ${ }^{14}$ Kenya, ${ }^{9}$ and Rwanda. ${ }^{20}$ The possible reason for low dietary diversity being more common among lower average monthly income households may be because having a good monthly income builds better opportunities to secure household food and provides purchasing capital for a variety of nutritious foods both inside and outside the home. Low income leads to a diet with poor nutrient adequacy which will be mainly based on low cost, least nutritious and monotonous food groups.

This study also revealed that duration on ART was another factor significantly associated with dietary diversity. It was noted that HIV patients on ART for less than than 1 year ( $<12$ months) duration were four times more likely to report low dietary diversity than those on ART for more than 1 year. This finding was consistent with the study conducted in Metema Hospital, ${ }^{14}$ Hiwot Fana and Dilchora Hospitals. ${ }^{7}$ The possible explanation for this might be that most ART drugs may lead to reduced food consumption or decreased nutrient absorption due to gastrointestinal tract related side-effects like vomiting, loss of appetite, diarrhea and dyspepsia, which aggravate the weight loss and nutritional problems experienced by HIV patients. In the early initiation period, this condition might increase the likelihood of having reduced food consumption, little meal frequency and poor dietary diversity because of adaptation problems. ${ }^{31}$

Dietary counseling was another predictors of dietary diversity among the study participants. Those adult HIV patients who got dietary counseling were more likely to have a diversified diet compared to those who did not have counseling. This finding is similar with the studies done in Motta Town, East Gojjam Zone, Northwest Ethiopia, ${ }^{22}$ and NairobiKenya. ${ }^{32}$ The possible explanation for this result might be that those HIV patients who got nutritional counseling had higher chance about awareness of nutrition impacts dietary diversity. As an individual's nutritional understanding increases, the consumption of foods from different food groups also growths. As a result, a diversity of nutrients are acquired and thus nutrient adequacy is achieved.

This study may have certain limitations such as recall bias and social desirability bias. Anthropometric measurement error is also another limitation. Our study includes its crosssectional nature, it does not show real association.

\section{Conclusions}

The magnitude of inadequate dietary diversity was a major nutritional problem in HIV patients attending ART clinics in the present study area. Low average monthly income, being female, duration of participants on ART, dietary counseling were the factors significantly associated with dietary diversity among HIV-positive 
Table 4 Factors Associated with Dietary Diversity in Public Hospitals of Kembata Tembaro Zone, Southern Ethiopia, 2019 ( $\mathrm{n}=314)$

\begin{tabular}{|c|c|c|c|c|c|}
\hline \multirow[t]{2}{*}{ Variables } & \multirow[t]{2}{*}{ Category } & \multicolumn{2}{|c|}{ Dietary Diversity Status } & \multirow{2}{*}{$\begin{array}{l}\text { COR } \\
(95 \% \mathrm{CI})\end{array}$} & \multirow{2}{*}{$\begin{array}{l}\text { AOR } \\
(95 \% \mathrm{CI})\end{array}$} \\
\hline & & Inadequate & Adequate & & \\
\hline \multirow[t]{2}{*}{ Sex } & Male & $73(50 \%)$ & 73 (50\%) & 1 & I \\
\hline & Female & $132(67.7 \%)$ & $63(32.3 \%)$ & $2.09(1.34-3.26)$ & $2.99(1.67-5.37)^{*}$ \\
\hline \multirow[t]{2}{*}{ Residence } & Urban & $99(54.1 \%)$ & $84(45.9 \%)$ & $0.57(0.37-0.89)$ & $0.67(0.38-1.16)$ \\
\hline & Rural & $106(67.1 \%)$ & $52(32.9 \%)$ & 1 & I \\
\hline \multirow[t]{2}{*}{ Food status } & Secure & $66(47.6 \%)$ & $72(52.2 \%)$ & 1 & I \\
\hline & Insecure & $139(68.5 \%)$ & $64(31.5 \%)$ & $1.79(1.51-3.70)$ & $1.22(0.68-2.18)$ \\
\hline \multirow[t]{2}{*}{ WHO stage of disease } & Stage I\&II & $156(57.1 \%)$ & $117(42.9 \%)$ & I & I \\
\hline & Stage III\&IV & $49(72.1 \%)$ & $19(27.9 \%)$ & $1.93(1.08-3.46)$ & $1.86(0.94-3.69)$ \\
\hline \multirow[t]{2}{*}{ Duration of ART } & $\leq 12$ months & $8(28.6 \%)$ & 20 (7I.4\%) & $4.24(1.81-9.94)$ & $3.77(1.42-10.02)^{*}$ \\
\hline & $>12$ months & $197(62.9 \%)$ & $116(37.1 \%)$ & 1 & I \\
\hline \multirow[t]{2}{*}{ Dietary counselling } & Yes & $137(55.5 \%)$ & $110(44.5 \%)$ & $0.47(0.28-0.79)$ & $0.54(0.30-0.97)^{*}$ \\
\hline & No & $68(72.3 \%)$ & $26(27.7 \%)$ & 1 & I \\
\hline \multirow[t]{2}{*}{ Meal frequency } & Less than three & $142(70.6 \%)$ & $59(29.4 \%)$ & $2.94(I .87-4.6 I)$ & $2.40(0.74-4.05)$ \\
\hline & More than three & $63(45.0 \%)$ & $77(55.0 \%)$ & 1 & 1 \\
\hline \multirow[t]{2}{*}{ Monthly income } & $\leq 1000$ & $138(70.4 \%)$ & $58(29.6 \%)$ & $2.77(1.77-4.33)$ & $1.82(1.04-3.17)^{*}$ \\
\hline & $>1000$ & $67(46.2 \%)$ & $78(53.8 \%)$ & 1 & I \\
\hline \multirow[t]{5}{*}{ Occupation } & Farmer & $56(27.3 \%)$ & $33(24.3 \%)$ & $0.5 \mathrm{I}(0.27-0.94)$ & $0.5 I(0.22-I .17)$ \\
\hline & Merchant & $38(18.5 \%)$ & $44(32.4 \%)$ & $1.26(0.58-2.7 I)$ & $0.33(0.14-0.76)$ \\
\hline & Gov't employed & $30(14.6 \%)$ & $14(10.3 \%)$ & $0.91(0.48-1.75)$ & $1.62(0.60-4.36)$ \\
\hline & House wife & $42(20.5 \%)$ & $27(19.9 \%)$ & $1.27(0.63-2.58)$ & $0.36(0.14-0.90)$ \\
\hline & Private employed & $39(19 \%)$ & $18(13.2 \%)$ & 1 & I \\
\hline \multirow[t]{2}{*}{ Any support } & Yes & $44(48.9 \%)$ & $46(51.1 \%)$ & $0.53(0.33-0.87)$ & $0.73(0.4|-| .3 \mid)$ \\
\hline & No & $16 \mid(64.1 \%)$ & $90(35.9 \%)$ & 1 & 1 \\
\hline
\end{tabular}

Note: *Significant at p-value $<0.05$.

Abbreviations: COR, crude odds ratio; $\mathrm{AOR}$, adjusted odds ratio; $\mathrm{Cl}$, confidence interval.

patients on ART. Therefore, zonal Health departments, health facilities and NGOs working on HIV and other stakeholders could work in cooperation to improve the problem among HIV patients through empowering females and sustainable income generating activities for HIV patients. Exceptional attention to nutritional care should be given for HIV patients and patients should be provided with appropriate counseling and support during the early initiation of ART. Further strong study design of a cohort is recommended.

\section{Abbreviations}

ART, antiretroviral treatment; BMI, body mass index; CI, confidence interval; DDS, dietary diversity score; FANTA, Food and Nutrition Technical Assistant; FAO, Food and Agricultural Organization; IDD, individual dietary diversity; HFIAS, Household Food Insecurity Access and
Scale; KTZ, Kembata Tembero zone; RERC, Research Ethics Review Committee; MRN, medical record number; SNNPR, Southern Nations Nationalities and Peoples Region; SSA, Sub-Saharan Africa; UNAIDS, United Nations Programme on HIV/AIDS.

\section{Data Sharing Statement}

All the data relevant for the manuscript are reported in tables. The raw data can be accessed from the corresponding author upon request.

\section{Acknowledgment}

We acknowledge Dire Dawa University research office for budget allocation and also thank KTZ Health Department, Durame Town Health Office for supporting our project. Our thanks are also extended to all study participants. 


\section{Author Contributions}

MM, TL, AM and ZT: Conceived and designed the study; MM, TL, and AM: adopted data collection instrument and acquisition of data; MM, TL, AM and ZT: Cleaned the data, analyzed the data and interpreted findings; $M M$ and TL: drafted the manuscript; MM, TL, AM and ZT: Critical revision and approval of the final manuscript. All authors made substantial contributions to conception and design, acquisition of data, or analysis and interpretation of data; took part in drafting the article or revising it critically for important intellectual content; agreed to submit to the current journal; gave final approval of the version to be published; and agree to be accountable for all aspects of the work.

\section{Disclosure}

The authors declare that they have no conflicts of interest for this work.

\section{References}

1. FAO. Guidelines for Measuring Household and Individual Dietary Diversity. Rome, Italy: FAO; 2010.

2. Musumari P, Wouters E, Kayembe P, et al. Food insecurity is associated with increased risk of nonadherence to antiretroviral therapy among HIV-infected adults in the Democratic Republic of Congo: a crosssectional study. PLoS One. 2014;9(1):1-10. doi:10.1371/journal.pone. 0085327

3. Scrimshaw NS, SanGiovanni JP. Synergism of nutrition, infection and immunity: an overview. Am J Clin Nutr. 1997;66(2):464S-77S. doi:10.1093/ajen/66.2.464S

4. Henary K. The Global HIV/AIDS Epidemic fact sheet. USAIDS. 2017.

5. WHO. Consolidated Guidelines on the Use of Antiretroviral Drugs for Treating and Preventing HIV Infection. switzerland: Geneva 27; 2015.

6. USAID. Multi-sectoral nutrition strategy technical gu idance brief; nutrition, food security and HIV. 2014.

7. Weldegebreal F, Digaffe T, Mesfin F, Mitiku H. Dietary diversity and associated factors among HIV positive adults attending antiretroviral therapy clinics at Hiwot Fana and Dilchora Hospitals, eastern Ethiopia. HIV/AIDS. 2018;10:63-72. doi:10.2147/HIV.S138638

8. Mangili A, Murman DH, Zampini AM, Wanke CA, Mayer KH. Nutrition and HIV infection: review of weight loss and wasting in the era of highly active antiretroviral therapy from the nutrition for healthy living cohort. Clin Infect Dis. 2006;42(6):836-842. doi: $10.1086 / 500398$

9. Beatrice M, Francis M. Factors affecting dietary intake and dietary diversity score among adults living with HIV/AIDS in Uasin Gishu District Hospital, Kenya: a cross sectional study. IOSR J Nurs Health Sci. 2018;7(6):10-18.

10. Amare M, Yusuf E, Beyen TK, Yenit MK. Factors associated with dietary diversity among HIV positive adults ( $\geq 18$ years) attending ART clinic at Mettema Hospital, Northwest Ethiopia: cross-sectional study. AIDS Clin Res. 2015;6(8).

11. Taye K, Alemayehu D, Tadesse E, Tiki T. Level of dietary diversity and associated factors among adult patients on HAART at public health facilities of Ambo town, West Shoa Zone Ethiopia. J Trop Dis. 2019;7(5)
12. Ja M. Barriers to Nutrition Management Among People Living with HIV on Antiretroviral Therapy. Colorado State University; 2011.

13. UNAIDS, WFP, WHO. HIV, food security and nutrition. 2008.

14. Woldemariam A, Yusuf M, Beyen T, Yenit M. Factors associated with dietary diversity among HIV positive adults ( $\geq 18$ years) attending ART clinic at Mettema Hospital, Northwest Ethiopia: cross-sectional study. J AIDS Clin Res. 2015;6(8). doi:10.4172/2155-6113.1000490

15. Jariwalla RJ, Niedzwiecki AMR. Role of micronutrients in the control of HIV and AIDS. 2007.

16. Graan AV, Vorster HH. What is the optimum diet for asymptomatic HIV-infected people? Public Health. 2007.

17. Mpontshane N, Broeck J, Chhagan M, Luabeya KKA, Johnson A HIV Infection Is Associated with Decreased Dietary Diversity in South African Children. 2008.

18. Akwiwu UN, Akinbile LA. Dietary intake adequacy of people living with HIV/AIDS in rural communities of Imo State, Nigeria. $J$ Agric Ext. 2017;21(1):218-230. doi:10.4314/jae.v21i1.18

19. Kassaw ME, Biks G, Belew A, Hunegnaw M. Predictors of dietary diversity among adults on antiretroviral therapy in Debre Tabor Hospital, northwest Ethiopia: a cross-sectional study. BMC Public hHealth. 2018.

20. Sirotin N, Hoover D, Segal-Isaacson CJ, et al. Structural determinants of food insufficiency, low dietary diversity and BMI: a crosssectional study of HIVinfected and HIV-negative Rwandan women. BMJ Open. 2012;2:000714. doi:10.1136/bmjopen-2011-000714

21. Palermo T, Rawat R, Weiser S, Kadiyala S, Beck EJ. Food access and diet quality are associated with quality of life outcomes among HIV-infected individuals in Uganda. PLoS One. 2013;8(4). doi:10.1371/journal.pone.0062353

22. Tesfaw A, Jara D, Temesgen H. Dietary diversity and associated factors among HIV positive adult patients attending public health facilities in Motta Town, East Gojjam Zone, Northwest Ethiopia Hindawi. Adv Public Health. 2018;2018:1-8. doi:10.1155/2018/ 6135482

23. The Federal Democratic Republic of Ethiopia Ministry of Health. FDROE. National Guidelines for HIV/AIDS and Nutrition. 2008.

24. FDROE. Nationla Nutrition Progarm 2016-2020. 2016.

25. FMOH. Nationla Guidelines for Comprehensive HIV Prevention, Care and Treatment. 2017.

26. KTZHD. Annual Report of Kembata Tembaro Zone Health Departement. Kembata Tembaro Zone Health Departement. 2016.

27. Coates J, Swindale A, Bilinsky P. Household Food Insecurity Access Scale (HFIAS) for measurement of food access: indicator guide. Food Nutr Tech Assist III Project. 2007;3.

28. Ayele TB, Alemseged F, Biadgilign S. Food insecurity and associated factors among HIV-infected individuals receiving highly active antiretroviral therapy in Jimma zone Southwest Ethiopia. Nutr J. 2012;11 (51): $1-8$.

29. Dereje GM, Kumera G, Eshete T, Feyera F, Ewunetu T. Food insecurity and its associated factors among people living with HIV/AIDS receiving anti-retroviral therapy at Butajira Hospital, Southern Ethiopia. Nutr Food Sci. 2014;5(2):1-6.

30. Asnakew M. Food insecurity: prevalence and associated factors among adult individuals receiving highly active antiretroviral therapy (HAART) in ART clinics of Hosanna Town, Hadiya Zone, Southern Ethiopia. Open Access Library J. 2015;2(1800):1-9.

31. Hoffmann C. Reducing Mortality with Cotrimoxazole Preventive Therapy at Initiation of Antiretroviral Therapy. Wolters Kluwer Health Lippincott Williams and Wilkins; 2010.

32. Muthamia OG, Mwangi AM, Mbugua SK. The effects of nutritional knowledge on the dietary practices of people living with HIV in Kayole division, Nairobi-Kenya. Int J Nutr Food Sci. 2014;3 (6):597-601. doi:10.11648/j.ijnfs.20140306.27 


\section{Publish your work in this journal}

HIV/AIDS - Research and Palliative Care is an international, peerreviewed open-access journal focusing on advances in research in HIV, its clinical progression and management options including

control viral spread. The manuscript management system is completely online and includes a very quick and fair peer-review system, which is all easy to use. Visit http://www.dovepress.com/testimonials.php to antiviral treatment, palliative care and public healthcare policies to read real quotes from published authors.

Submit your manuscript here: https://www.dovepress.com/hivaids—research-and-palliative-care-journal 